\title{
Sleep Quality and Associated Risk Factors in Leukemia Patients Undergoing Chemotherapy in Iran
}

\author{
Masoumeh Bagheri-Nesami ${ }^{1}$, Amir Hossein Goudarzian ${ }^{2 *}$, Ghasem Jan Babaei ${ }^{3}$, \\ Milad Badiee $^{2 *}$, Mostafa Mousavi², Mohammad Sadegh Sharifi ${ }^{2}$
}

\begin{abstract}
This study aimed to determine sleep disorders and associated risk factors in leukemia patients undergoing chemotherapy in Imam Khomeini Hospital of Sari, Iran. This cross-sectional study was conducted in 2015 with 100 patients selected. Inclusion criteria included complete mental and psychological health and being over 18 years old, and exclusion criteria included suffering other cancers, other chronic diseases, concurrent radiotherapy, and chemotherapy. The Pittsburgh Sleep Quality standard questionnaire was used to collect data. The questionnaire consisted of mental sleep quality, sleep latency, sleep duration, sleep quality, sleep disturbances, use of sleeping drugs, and impaired daily functioning. Data were analyzed by software SPSS 18 and by using descriptive and inferential tests (Pearson, Spearman, T-test and chi-square). Totals of 47 men (47\%) and 53 women (53\%) with a mean age of $44.1 \pm 1.7$, participated in the study. The mean overall score of sleep quality was $9.3 \pm 3.9$, which represents the average sleep quality in most participants. T-test shows that males have better sleep quality than females $(\mathrm{t}=2.1 ; 95 \% \mathrm{CI}: 0.004-0.25 ; \mathrm{P}<0.01)$. Also the sleep quality increased with age $(\mathrm{r}=0.22, \mathrm{P}=0.03)$. Results show that the amount of sleep quality was only moderate in most patients, so it is necessary to take coping strategies to improve their quality of sleep.
\end{abstract}

Keywords: Leukemia - sleep disorders - chemotherapy - Iran

Asian Pac J Cancer Prev, 17, Cancer Control in Western Asia Special Issue, 107-111

\section{Introduction}

Leukemia results from abnormal changes of bone marrow's blood cells which is accompanied with increased growth in the number of abnormal cells and decreased production of normal blood cells, it is divided into two categories: acute and chronic leukemia (Smith et al., 2014). Acute leukemia includes acute myelocytic leukemia (AML) with an incidence of $46 \%$ and acute lymphoblastic leukemia (ALL) with a prevalence of $11 \%$ and chronic leukemia includes chronic myelocytic leukemia (CML) with a prevalence of $14 \%$ and chronic lymphocytic (CLL) with an prevalence of $29 \%$ (Greenberg et al., 2013). Cancer is the second leading cause of death in most industrialized and advanced countries and one of the most dangerous and painful diseases; According to official statistics in 2007, 9.7 million people died of cancer and evidence suggests that it will increase up to 11.5 million in 2030 (Smith et al., 2014). Cancer spreads undeniably in the country especially in Mazandaran (North of Iran) and causes morbidity and mortality in the different age groups which leads to huge costs in terms of diagnosis and treatment for patients` families and health system of the country (Tahmasebi et al., 2006). This disease is spread around the world so that it includes $4 \%$ of all cancers and $4 \%$ of deaths from cancers (Rayar et al., 2012).

Leukemia has symptoms such as anorexia, fatigue, irritability, mild fever, bone or joint pain, pallor, bleeding from the nose, anemia, thrombocytopenia, neutropenia and skin rash and may be associated with lymphadenopathy and splenomegaly (Kaspers et al., 2007; Chao et al., 2013; Gözdaşoğlu et al., 2002). The depression resulted from the disease and its treatment, sleep disorders, pain and cognitive changes are some abnormalities which affect these patients (Kaleyias et al., 2012). Sleeping is one of the most important cycles during day and night and it also is a sophisticated biological pattern (Moller et al., 2012). Almost a third of adults suffer from insomnia which it increases up to approximately 69 percent with increased age and chronic diseases (Zhang et al., 2007). Also according to the research, insomnia weakens physical strength and causes stress and anxiety (Björnsdóttir et al., 2013); it also affects the central nervous system (Baglioni et al., 2011). Gooneratne and colleagues (2007) in a study to examine sleep and quality of life of patients who had lung cancer concluded that $56 \%$ of patients had poor sleep 
quality. He and colleagues (2015) with investigating sleep quality in patients with DTC (Differentiated Thyroid Cancer) stated that $54.32 \%$ of patients suffer from poor sleep quality. Sleep disorders can be caused by external factors such as noise, light, frequent interventions by personnel or internal factors such as pain, excitement, depression and stress. Davinson and his colleagues claimed that most of sleep disorders and sleeping drug application was related to patients with lung cancer. In comparing different types of cancer, they reported that people with gastrointestinal cancer suffer less from insomnia and fatigue (Dogan et al., 2015).

According to the available database, no study regarding sleep disorders and leukemia was carried out in Mazandaran province. Due to increasing number of this terrible disease in Northern provinces of Iran especially in Mazandaran province. This study aimed to determine the sleep quality and some related factors in leukemia patients undergoing chemotherapy in Imam Hospital of Sari city in 2015 .

\section{Materials and Methods}

This descriptive-analytic study was conducted in the city of Sari in 2015 (June 22 -15 September). The samples consisted of patients admitted in oncology ward of Imam Khomeini hospital in Sari city who were undergoing chemotherapy. Research team members include statistical consultant, specialist in blood diseases and nurses trained to collect data. After verification of leukemia through the patient's clinical records, at first, the participants were given explanations about the objectives of the research in order for each of them to be excluded from the study in case they do not want to cooperate. Next, the participants in the study were asked to give a written consent. Some of the parameters of the study consent form include confidentiality of information, providing participants with the results if asked and leaving the study at the request of individuals. Inclusion criteria involved mental health and being over 18 and exclusion criteria included having other cancers and chronic diseases and concurrent radiotherapy and chemotherapy. Demographic and medical questionnaire included variables such as type of disease, history of disease, age, sex, marital status, education level, employment status, sufficient monthly income to make a living.

\section{Instrument}

Pittsburgh Sleep Quality Index (PSQI) was another tool that was used in this study including areas such as delays in falling asleep, sleep duration, sleep efficiency (the ratio of duration of useful sleep and total time spent in bed), sleep disorders (defined as waking at night), hypnotic drug consumption and morning performance (defined as the difficulties experienced by people during the day due to sleeping badly at night). The score of each scale of the questionnaire is considered based on the Likert scale from 0 to 3 and the range of changes is 0 to 21 (Farrahi Moghaddam et al., 2012). Based on the cut-off point of this scale a score equal to or higher than 5 is considered as a significant sleep disorder and a score less than 5 is indicating good condition of sleeping. This questionnaire examined patient attitudes towards sleep quality during the past 4 weeks. According to the study of Hassan pour (2006) on patients with cancer, reliability of this tool was confirmed. Also Buysse et al (1989). Confirmed internal validity of this tool on 168 people (sensitivity $89.6 \%$, specificity $86.5 \%$ and kappa coefficient 0.75 ). Using Cronbach's alpha test, Ghanbari Jolfaei et al (2014) measured its reliability to be 0.83 by investigating patients receiving chemotherapy in Tehran (Capital of Iran). In this study, reliability of Pittsburgh`s questionnaire was confirmed by test-retest method on 30 leukemia patients with more than 0.89 .

\section{Data analysis}

After confirming the data normality by Kolmogorov-Smirnov test $(\mathrm{P}=0.7)$, data was analyzed by SPSS 18.0 statistical software. At first in order to investigate variables mean (SD) and frequency percentage were used. Pearson correlation was used to determine the relationship between PSQI variable items. Independent student t-test was used to compare sleep quality in both gender groups. Spearmancorrelation coefficientand chi-square testwasused to determine the relationship between PSQI and demographic variables. Significant level of $\mathrm{P}<0.05$ was considered

\section{Results}

Among 100 participants, 47 male (47\%) and 53 female $(53 \%)$ have been assessed with the average age of 44.08 years ( $\mathrm{SD}=1.7 ; 95 \% \mathrm{CI}: 40.7-47.5)$. Most of them were married $(69 \%)$ and have under diploma graduate (57\%). 39 (39\%) of patients were households and have an intermediate income status. Distribution of various types of leukemia (AML, ALL and CML) were $47(47 \%), 51(51 \%)$ and $2(2 \%)$ respectively. As an indicated in table 3, Spearman test shows that all dimentions have positive and significant association with patients sleep quality $(\mathrm{P}<0.05)$. The average score of sleep quality was $9.3(\mathrm{SD}=3.9 ; 95 \% \mathrm{CI}: 8.6-10.1)$ that most of patients $(89 \%)$ had different levels of sleep

Table 1. Frequency, Mean and Standard Deviation of Quality of Sleep Variables

\begin{tabular}{|c|c|c|c|c|c|c|c|}
\hline variables & $\begin{array}{c}\text { Subjective } \\
\text { quality of sleep }\end{array}$ & Sleep latency & Sleep duration & $\begin{array}{l}\text { Use of sleeping } \\
\text { medication }\end{array}$ & $\begin{array}{c}\text { Sleep } \\
\text { disturbances }\end{array}$ & $\begin{array}{c}\text { Daytime } \\
\text { dysfunction }\end{array}$ & Sleep quality \\
\hline & $\begin{array}{llll}a & b & c & d\end{array}$ & $\mathrm{~b}$ & b $\quad c \quad d$ & e $\mathrm{f}$ & $\begin{array}{llll}a & b & c & d\end{array}$ & $\begin{array}{llll}a & b & c & d\end{array}$ & $\begin{array}{llll}a & b & c & d\end{array}$ \\
\hline $\mathrm{N}=100$ & $\begin{array}{llll}8 & 51 & 22 & 19\end{array}$ & $\begin{array}{llll}17 & 23 & 36 & 24\end{array}$ & $\begin{array}{llll}33 & 25 & 13 & 29\end{array}$ & $\begin{array}{llll}53 & 16 & 13 & 18\end{array}$ & 129646 & $\begin{array}{llll}18 & 45 & 18 & 19\end{array}$ & $\begin{array}{llll}57 & 26 & 10 & 7\end{array}$ \\
\hline $\operatorname{Mean}(\mathrm{SD})$ & $1.5(0.9)$ & $2.8(1.8)$ & $1.4(1.2)$ & $0.9(1.2)$ & $11.6(4.5)$ & $2.4(2.1)$ & $82.5(13.3)$ \\
\hline
\end{tabular}

Note: $\mathrm{a}=$ exellent; $\mathrm{b}=$ good; $\mathrm{c}=$ average; $\mathrm{d}=$ bad; $\mathrm{e}=$ never; $\mathrm{f}=$ less than once per week; $\mathrm{g}=$ once and twice per week; $\mathrm{h}=2,3$ or more times/week. 
Table 2. Mean and Standard Deviation of Quality of Sleep in Diffrent Type of Leukemia

\begin{tabular}{lllc}
\hline \multirow{2}{*}{ Leukemia types } & \multicolumn{3}{c}{ Global quality of sleep } \\
& Mean (SD) & SE & $95 \%$ CI \\
\hline AML & $9.4(3.6)$ & 0.5 & $8.3-10.5$ \\
ALL & $9.2(4.2)$ & 0.6 & $8-10.4$ \\
CML & $10.5(2.1)$ & 1.5 & $-8.5-29.5$ \\
Total & $9.3(3.9)$ & 0.4 & $8.6-10.1$ \\
\hline
\end{tabular}

disorders (Table 1 and 2).

It can be said that, almost global quality of sleep in ALL patients is higher than other types (Table 2). Table 4 declares that sleep quality in married patients was more than singles and there was no association between educational level and income status with sleep quality. T test shows that males have more sleep quality than females $(\mathrm{t}=2.1 ; 95 \% \mathrm{CI}: 0.004-0.2 ; \mathrm{P}<0.01)$. Self- quality was worst in older patients against youngers $(\mathrm{P}=0.03, \mathrm{r}=0.2)$.

\section{Discussion}

This study aimed to determine the amount of sleep disorders in patients undergoing chemotherapy for leukemia. According to the study, mean score of sleep quality in patients was expressed to be (95\% CI: 8.6-10.1) $9.3 \pm 3.9$. In line with the findings of the present study, Mystakidou and colleagues (2007) based on their study on patients with leukemia conducted that these patients have poor sleeping quality. Anderson and colleagues (2003) in a study to determine the fatigue and sleep disorders in patients with cancer stated that 65 per cent of these patients have sleep disorders. This figure is higher in the present study which shows the importance of this issue and demands follow-up actions. Sleeping is affected by mental and physical health. Pain and depression, restriction of daily activities and reduced quality of life in patients with cancer are some factors that reduce the quality of their sleep (Cohen et al., 2004). Palesh and colleagues (2010) in a study conducted on patients with various types of cancer found out that there is a high prevalence between symptoms and sleep disorder syndrome. He and colleagues (2015) in a study conducted on patients with thyroid cancer before treatment, obtained the score of sleep quality to be with PSQI $4.2 \pm 7.6$ and stated that 54.3 percent of people suffer from sleep disorders. Dean and his colleagues (2013) investigated sleep quality inpatients who are being treated for lung cancer and reported that $55 \%$ of patients have poor sleep quality which was lower compared with the present study. This difference in the percentage of disorder in the mean score of sleep quality can be due to differences in condition of the ward, sample size, inclusion and exclusion criteria and the type of cancer.

In this study, most patients mentioned that delay in sleeping and sleep disorder were the reasons for their insomnia. Savard and colleagues (2001) in a study stated that the main causes of sleep problems are delays in falling asleep, waking up during the night, waking in the early morning and reluctance to sleep. In the study of Venables (2014) on patients treated in oncology ward of hospital, delays in falling asleep and staying up during night were mentioned to be main sleep disorders, which are consistent with the present study. The use of sleeping medication is among factors which have had the least use in this study while Noroozi and colleagues (2012) in their study conducted on breast cancer patients receiving chemotherapy defined the use of sleeping mediation as widely used indicators. In the study by Cohen et al (2004). waking up during the night, not going back to sleep and not getting enough sleep were the major problems, in this study, most people had enough quantity of sleep. Age, sex and marital status were variables related to sleeping quality in this study. Sleep disorder increases with an increase in patients' age. Variables such as income and education levels had no significant relationship with sleep disorders. Palesh and colleagues (2010) stated sleep disorder increases with an increase in age and sleep

Table 3. Association of Quality of Sleep Dimensions

\begin{tabular}{|c|c|c|c|c|c|c|c|c|}
\hline Variables & 1 & 2 & 3 & 4 & 5 & 6 & 7 & 8 \\
\hline $\begin{array}{l}\text { 1. Subjective } \\
\text { quality of sleep }\end{array}$ & 1.0 & & & & & & & \\
\hline 2. Sleep latency & $<0.01(0.3)$ & 1.0 & & & & & & \\
\hline $\begin{array}{l}\text { 3. Sleep } \\
\text { duration }\end{array}$ & $0.1(0.2)$ & $0.02(0.2)$ & 1.0 & & & & & \\
\hline $\begin{array}{l}\text { 4. Use of } \\
\text { sleeping } \\
\text { medication }\end{array}$ & $<0.01(0.3)$ & $0.30(0.2)$ & $0.3(-0.1)$ & 1.0 & & & & \\
\hline $\begin{array}{l}\text { 5. Sleep } \\
\text { disturbances }\end{array}$ & $<0.01(0.4)$ & $0.14(0.1)$ & $<0.01(0.3)$ & $0.07(0.5)$ & 1.0 & & & \\
\hline $\begin{array}{l}\text { 6. Daytime } \\
\text { dysfunction }\end{array}$ & $<0.01(0.3)$ & $0.50(0.1)$ & $0.03(0.2)$ & $<0.01(0.4)$ & $<0.001(0.4)$ & 1.0 & & \\
\hline 7. Sleep quality & $0.01(-0.3)$ & $<0.01(-0.4)$ & $<0.01(-0.5)$ & $0.40(0.1)$ & $<0.01(-0.2)$ & $0.30(-0.1)$ & 1.0 & \\
\hline $\begin{array}{l}\text { 8. Global } \\
\text { quality of sleep }\end{array}$ & $<0.01(0.3)$ & $<0.01(0.4)$ & $<0.01(0.3)$ & $0.04(0.2)$ & $<0.01(0.4)$ & $<0.01(0.3)$ & $0.03(0.2)$ & 1.0 \\
\hline
\end{tabular}


Table 4 . Some Predictors of Patients Quality of Sleep

\begin{tabular}{lccc}
\hline & Education & Income status & Marital status \\
\hline $\mathrm{P}$ & 0.3 & 0.2 & $0.041^{*}$ \\
$95 \% \mathrm{CI}$ & $0.3-0.32$ & $0.21-0.22$ & $0.04-0.05$ \\
\hline$* \mathrm{P}<0.05$ & & &
\end{tabular}

disorders are fewer in men than in women, although this difference is small. Beck and colleagues (2010) concluded in their study that there is a Significant relationship between age and sleep quality so that sleep quality decreases as patients' age increases. They also suggested that education is not associated with sleep quality. Noroozi and colleagues (2012) stated that demographic variables such as age, marital status, education level are not related to sleeping and the length of the disease course is one of the significant variables in sleep quality and expressed that sleep disorders increases as the course of the disease increases. The difference of the environment and personnel and also cultural factors can be among the possible causes of these discrepancies.

Given the unfavorable situation of sleep quality in patients undergoing chemotherapy in the present study, it seems that measures such as positive changes in the resting place of the patients, reducing environmental stimuli and appropriative consultation are necessary. Access to a limited number of patients in a oncology unit, possible inaccuracies in answering the questions in some situations, such as patients' lethargy were some of the limitations of this study. In this regard, it is recommended that in the future more detailed and precise studies be done on patients with cancer, such as leukemia.

\section{Acknowledgments}

The authors would like to thank all the officials of Imam Khomeini Hospital of Sari and patients for their participation in this survey. In addition, we wish to thank the Research and Technology Deputy and Student Research Committee of Mazandaran University of Medical Sciences for their financial supports. The number code of this research was 193 that is approved in 2015.

\section{References}

Anderson KO, Getto CJ, Mendoza TR, et al (2003). Fatigue and sleep disturbance in patients with cancer, patients with clinical depression, and community-dwelling adults. J Pain Symptom Manage, 25, 307-18.

Björnsdóttir E, Janson C, Sigurdsson JF, et al (2013). Symptoms of insomnia among patients with obstructive sleep apnea before and after two years of positive airway pressure treatment. Sleep, 36, 1901-9.

Baglioni C, Battagliese G, Feige B, et al (2011). Insomnia as a predictor of depression: a meta-analytic evaluation of longitudinal epidemiological studies. J Affect Disord, 135, 9-10.

Buysse DJ, Reynolds CF, Monk TH, et al (1989). The pittsburgh Sleep Quality Index: A new instrument for psychiatric practice and research. Psychiatry Res, 28, 193-213.

Beck SL, Berger AM, Barsevick AM, et al (2010). Sleep quality after initial chemotherapy for breast cancer. Support Care Cancer, 18, 679-89.
Chao YH, Sheu JN, Chen SM, et al (2013). Diagnostic paracentesis in an acute lymphoblastic leukemia child without characteristic symptoms of pancreatitis. $J$ Pediatr Hematol Oncol, 35, 47.

Cohen L, Warnek C, Rachel Fouladi R, et al (2004). Psychological adjustment and sleep quality randomized of the effects of atibet a yoga intervention in patients with lymphoma. Cancer, 100, 2253-60.

Dogan O, Ertekin S, Dogan S (2005). Sleep quality in hospitalized patients. J Clin Nurs, 14, 107-13.

Dean GE, Redeker NS, Wang Y, et al (2013). Sleep, Mood, and Quality of Life in Patients Receiving Treatment for Lung Cancer. Oncol Nurs Forum, 40, 441-51.

Elizabeth Venables H (2014). Sleep problems in cancer: effective psychological interventions- a systematic review. Res Medica, 22, 15-36.

Farrahi Moghaddam J, Nakhaee N, Sheibani V, et al (2012). Reliability and validity of the Persian version of the Pittsburgh Sleep Quality Index (PSQI-P). Sleep Breath, 16, 79-82.

Greenberg EM, Probst A (2013). Chronic Leukemia. Crit Care Nurs Clin North Am, 25, 459-70.

Gözdaşoğlu S, Yavuz G, Unal E, et al (2002). Orbital granulocytic sarcoma and AML with poor prognosis in Turkish children. Leukemia, 16, 962.

Gooneratne NS, Dean GE, Rogers AE, et al (2007). Sleep and quality of life in long-term lung cancer survivors. Lung Cancer, 58, 403-10.

Ghanbari Jolfaei A, Makvandi A, Pazouki A (2014). Quality of sleep for hospitalized patients in Rasoul-Akram hospital. Med J Islam Repub Iran, 28, 73-8

He Y, Meng Z, Jia Q, et al (2015). Sleep quality of patients with differentiated thyroid cancer. PLoS One, 10, e013063-4.

Hasanpour Dehkordi A (2006). Factors affecting quality of life in cancer patients under chemotherapy in Tehran (2004). $J$ Kermanshah Univ Med Sci, 10, 110-9.

Kaspers GJ, Zwaan CM (2007). Pediatric acute myeloid leukemia: towards high-quality cure of all patients. Haematologica, 92, 1519-32.

Kaleyias J, Manley P, Kothare SV (2012). Sleep disorders in children With cancer. Semin Pediatr Neurol, 19, 25-34.

Moller T, Adamsen L, Appel C, et al (2012). Health related quality of life and impact of infectious comorbidity in outpatient management of patients with acute leukemia. Leuk Lymphoma, 53, 1896-904.

Mystakidou K, Parpa E, Tsilika E, et al (2007). The relationship of subjective sleep quality, pain, and quality of life in advanced cancer patients. Sleep, 30, 737-42.

Norozi M (2012). Quality of sleep and related factor in breast cancer patients receving chemotherapy in Qom 2011. Iran $J$ Breast Dis, 4, 51-60.

Palesh OG, Roscoe JA, Mustian KM, et al (2010). Prevalence, demographics, and psychological associations of sleep disruption in patients with cancer: University of Rochester Cancer Center-Community Clinical Oncology Program. $J$ Clin Oncol, 28, 292-8.

Rayar MS, Nayiager T, Webber CE, et al (2012). Predictors of bony morbidity in children with acute lymphoblastic leukemia. Pediatr Blood Cancer, 59, 77-82.

Smith MA, Altekruse SF, Adamson PC, et al (2013). Declining childhood and adolescent cancer mortality. Cancer, 120, 2497-506.

Savard J, Simard S, Blanchet J, et al (2001). Prevalence, clinical characteristics, and risk factors for insomnia in the context of breast cancer. Sleep, 24, 583-90.

Tahmasebi B, Mahmoudi M, Yahya Pour Y, et al (2006). Determination and comparison of incidence rate and trend 
DOI:http://dx.doi.org/10.7314/APJCP.2016.17.S3.107

Sleep Quality and Associated Risk Factors in Leukemia Patients Undergoing Chemotherapy in Iran

of morbidity of leukemia and lymphoma in Mazandaran province. J Mazandaran Univ Med Sci, 16, 87-9.

Zhang J, Li F, Lin Y, et al (2007). Subjective sleep quality in perimenopausal women and its related factors. J Nanjing Med Univ, 21, 116-9. 